\title{
Cyclosporiasis and other intestinal parasitoses in association with diarrhoea in Ilorin, Nigeria
}

\author{
Babatunde, Shola Kola ${ }^{1 *}$, Fadeyi, Abayomi ${ }^{2}$, Akanbi II, Ajibola Ahmed ${ }^{2}$, Nwabuisi, Charles ${ }^{2}$ \\ and Abdulraheem, Jimoh Yemi ${ }^{3}$ \\ ${ }^{1}$ Department of Biosciences and Biotechnoloy, College of Pure and Applied Sciences, Kwara State University, \\ Malete. P. M. B. 1533. Kwara State, Nigeria \\ ${ }^{2}$ Department of Medical Microbiology and Parasitoloy, Faculty of basic Medical Sciences, College of Health Sciences, \\ University of Ilorin, Kwara State, Nigeria. \\ ${ }^{3}$ Department of Medical Microbiology and Parasitoloy, University of Ilorin Teaching Hospital, Ilorin, Kwara State, Nigeria.
}

Accepted 26 April, 2013

\begin{abstract}
This study assessed the profile of intestinal parasites associated with diarrhoea among patients with the history of gastrointestinal illness and those without history of gastrointestinal illness prior to time of sample collection. Both wet mount preparation and formol-ether concentration methods were used to detect intestinal parasites in 1,040 stool samples. Smears were made from deposits of formol-ether concentration, air dried, fixed and stained with modified Ziehl-Neelsen method. The results show the presence of cyst/oocysts of six protozoan parasites and seven ova/larvae of helminth parasites. Cryptosporidium species, Cyclospora cayetanensis and Entamoeba histolytica/dispar had the highest prevalence of $23.8,21.2$ and $15.4 \%$, respectively. The prevalence of regular parasites was generally low, the highest being Ascaris lumbricoides (6.5\%) and Hookworm (4.2\%). The prevalence of Cyclospora cayetanensis is more $(29.4 \%)$ among the patients with gastrointestinal illness than among those without gastrointestinal illness (12.1\%) but the difference was not significant ( $P$ value $\mathbf{0 . 1 2}$ ). The implication of these findings is discussed and it was suggested that Hospital laboratories in tropical countries should include Cyclospora cayetanensis in the diagnosis of unexplained diarrhoea.
\end{abstract}

Key words: Cyclospora cayetanensis, Cryptosporidium species, intestinal parasitoses, diarrhoea, Ilorin.

\section{INTRODUCTION}

Infection of the gastrointestinal tract, especially infectious diarrhoea is one of the most important health problems afflicting people of all ages around the world (WHO, 1990, 2000; Ellicott, 2007). In many heavily populated and developing nations, deaths from diarrhoea illnesses exceed those from any other single cause (Gurrent and McAullife, 1986; Popovici et al., 2003). Diarrhoea diseases are the leading cause of childhood death (Synder and Marson, 1982; Helmy, 2010) especially in developing countries where the absence of potable drinking water, and good faecal disposal system exists; in addition to other contributory factors such as poor personal hygienic practice and low level of health education (Farting, 2000). A number of agents are associated with human diarrhoea including major types of microorganisms: bacteria, viruses and parasites. Protozoan parasites that are associated with diarrhoea in tropical Africa include Giardia lamblia, Entamoeba histolytica and Balantidium coli, and recently the coccidian agents such as Cryptosporidium, Isospora belli, Microsporidia and Cyclospora cayetanensis (Wilson, 1999; Raminez et al., 2004; Quivoz et al., 2000). 
Cyclosporiasis is an emerging infectious disease that was first described in humans living in Papua New Guinea in 1977 (Logar et al., 1997). The causative agent Cyclospora cayetanenesis is a coccidian parasite that was initially labelled with various names including fungal spores, cyanobacteria-like bodies, blue-green algae and large (big) Cryptosporidia (Ortega et al., 1994). The organism was initially known as pathogen of moles, snakes, rodents and fowls. Although the organism is known to occur worldwide, it is transmitted into human through contaminated food and water containing sporulated infective oocysts. The disease is characterized with diarrhoea, flatulence, fatigue and abdominal pain in both immunocompetent and immunocompromised persons irrespective of sex and age (Shields and Olson, 2003; Connor et al., 2001). Cyclospora belongs to the Eimeria clade and Phylum apicomplexia (Ortega et al., 1994, 1998). The species designation Cyclospora cayetanensis was given 1994 to Peruvian isolates of human-associated Cyclospora (Ortega and Sanchez, 2010; Lopez et al., 1998).

A number of documents exist on coccidian parasites and its their association with diarrhoea in developed countries, however, very few reports of this parasite have been documented from continent of Africa. This may be because researchers and physicians were either not aware of the existence of this pathogen or its possibility of being responsible for unexplained diarrhoea. The causative agents of diarrhoea should be properly investigated in the laboratory so that appropriate treatment can be provided. This work aimed at providing information on profile of intestinal parasites that may induce diarrhoea including the 'newer' coccidian agents such as Cryptosporidium species and Cyclospora cayetanensis among patients attending University of Ilorin Teaching Hospital.

\section{MATERIALS AND METHODS}

This study was conducted at the University of Ilorin Teaching Hospital, Ilorin. Ilorin is the capital of Kwara State, in middle belt of Nigeria. This Hospital serves patients from other neighbouring States such as Niger, Kogi, Ekiti, Osun and Oyo. The population of llorin was 1.2 million 2006 census (NPC, 2006). One thousand and forty (1040) consecutive samples retrieved from daily submission to the Department of Medical Microbiology and Parasitology laboratory after the results were released to patients or wards were used for this study. The patients' biodata and clinical information were obtained from request forms. These samples were preserved in $10 \%$ formalin until examined. Patients' data were obtained from accompanied request forms including the clinical diagnosis. Patients without clinical diagnosis that could not give information about diarrhoea status were excluded from the study.

Direct microscopic examination of faecal specimen was performed in fresh physiologic saline and with Dobell's iodine. All the preparations were examined microscopically using Olympus microscope at 10X objective. A 40x objective was used to confirm the species of parasite seen and several microscopic fields were examined with this objective before reporting a specimen as no parasite found.
Ridley modified formol ether concentration technique (Ridley and Hawgood, 1965) was used to improve on the recovery of the cysts/oocysts and ova/larvae of protozoan and helminth parasites respectively from the samples that were missed in wet preparation. Ova/larvae and cysts were identified as previously described (Cheesbrough, 2005). Another smear of the deposit of formol-ether concentration was made on a new clean slide. This was allowed to air dried and stained with the modified Ziehl-Neelsen technique (Cheesbrough, 2005). Stained slides were examined under the oil immersion objective of microscope fitted with eye-piece micrometer and previously calibrated stage micrometer, to determine the size of the oocysts. Oocysts of Cyclospora cayetanensis were pinkish red with green background and were slightly bigger $(8$ to $10 \mu \mathrm{m})$ in diameter than oocysts of Cryptosporidium (6 to $7 \mu \mathrm{m})$ with same green background as previously described (Cheesbough, 2005). Data was analysed using Epi. Info., Stool parasites were compared by Chi-square and Fisher exact tests. Differences were regarded as significant when $\mathrm{P} \leq 0.05$.

\section{RESULT}

A total of 1,040 faecal samples were collected and examined, $560(53.8 \%)$ were from male patients while $480(46.2 \%)$ were from female patients. Out of 1,040 specimens, $496(47.7 \%)$ were from healthy individuals that came for medical tests or routine check-ups, without prior history of gastrointestinal illness. The others 544 $(52.3 \%)$ were patients with clinical cases symptoms of gastrointestinal tract infection. Six different cysts/oocysts of protozoan parasites were detected, while seven ova/larvae of different helminth parasites were also detected. Out of 1,040 samples examined, at least one parasitic ovum/larva, cyst or oocyst was detected in 592 (56.9\%) patients (Table 1 ).

There were more parasites detected among age group 41 to 50 years $(77.8 \%)$ patients with diarrhoea than the same age group (40\%) without diarrhoea, while age group that were sixty years and above had the least parasites detection among patients with diarrhoea, parasites were not detected in the same age group without diarrhoea (Figure 1).

Figure 1 illustrates the distribution of parasites among the participated patients with history of diarrhoea and those without history of diarrhoea. Cryptosporidium species had the highest occurrence in both categories of patients with prevalence of 31.6 and $15.3 \%$ respectively. This was closely followed by Cyclospora cayetanensis with prevalence of 29.4 and $12.1 \%$ among patients with diarrhoea and those without diarrhoea respectively. Other intestinal parasites such as Taenia species and Schistosoma mansoni had low prevalence of $0.4 \%$ each in patients with diarrhoea, while they were not detected at all in patients without diarrhoea (Table 2).

Table 2 illustrates the distribution of Cryptosporidium species, Cyclospora cayetanensis and co-infection with both Cryptosporidium species and Cyclospora cayetanensis. There was higher prevalence of coinfections Cryptosporidium species/Cyclospora cayetanensis $(34.7 \%)$ in patients with diarrhoea than in 
Table 1. Distribution of parasites among patients with and without diarrhoea according to age group, Ilorin, November, 2011-October, 2012.

\begin{tabular}{lcccccc}
\hline \multirow{3}{*}{ Age group } & \multicolumn{3}{c}{ Diarrhoea } & \multicolumn{3}{c}{ non-diarrhoea } \\
\cline { 2 - 7 } & Total & $\begin{array}{c}\text { Parasites } \\
\mathbf{N}(\%)\end{array}$ & $\begin{array}{c}\text { No parasite } \\
\mathbf{N}(\%)\end{array}$ & Total & $\begin{array}{c}\text { Parasites No } \\
\mathbf{N}(\%)\end{array}$ & $\begin{array}{c}\text { No Parasite } \\
\mathbf{N}(\%)\end{array}$ \\
\hline $0-10$ & 100 & $60(60)$ & $40(40)$ & 76 & $28(36.8)$ & $48(63.2)$ \\
$11-20$ & 84 & $64(76.2)$ & $20(23.8)$ & 128 & $60(46.9)$ & $68(53.1)$ \\
$21-30$ & 172 & $108(62.8)$ & $64(37.2)$ & 128 & $64(50.0)$ & $64(50.0)$ \\
$31-40$ & 88 & $60(68.2)$ & $28(31.8)$ & 72 & $44(61.1)$ & $28(38.9)$ \\
$41-50$ & 36 & $28(77.8)$ & $8(22.2)$ & 40 & $16(40)$ & $24(60.0)$ \\
$51-60$ & 36 & $24(66.7)$ & $12(33.3)$ & 48 & $20(41.7)$ & $28(58.3)$ \\
$61>$ & 28 & $16(57.1)$ & $12(42.9)$ & 4 & $0(0)$ & $4(100)$ \\
& $544(52.3)$ & $360(66.2)$ & $184(33.8)$ & $496(47.9)$ & $232(46.8)$ & $264(53.2)$ \\
\hline
\end{tabular}

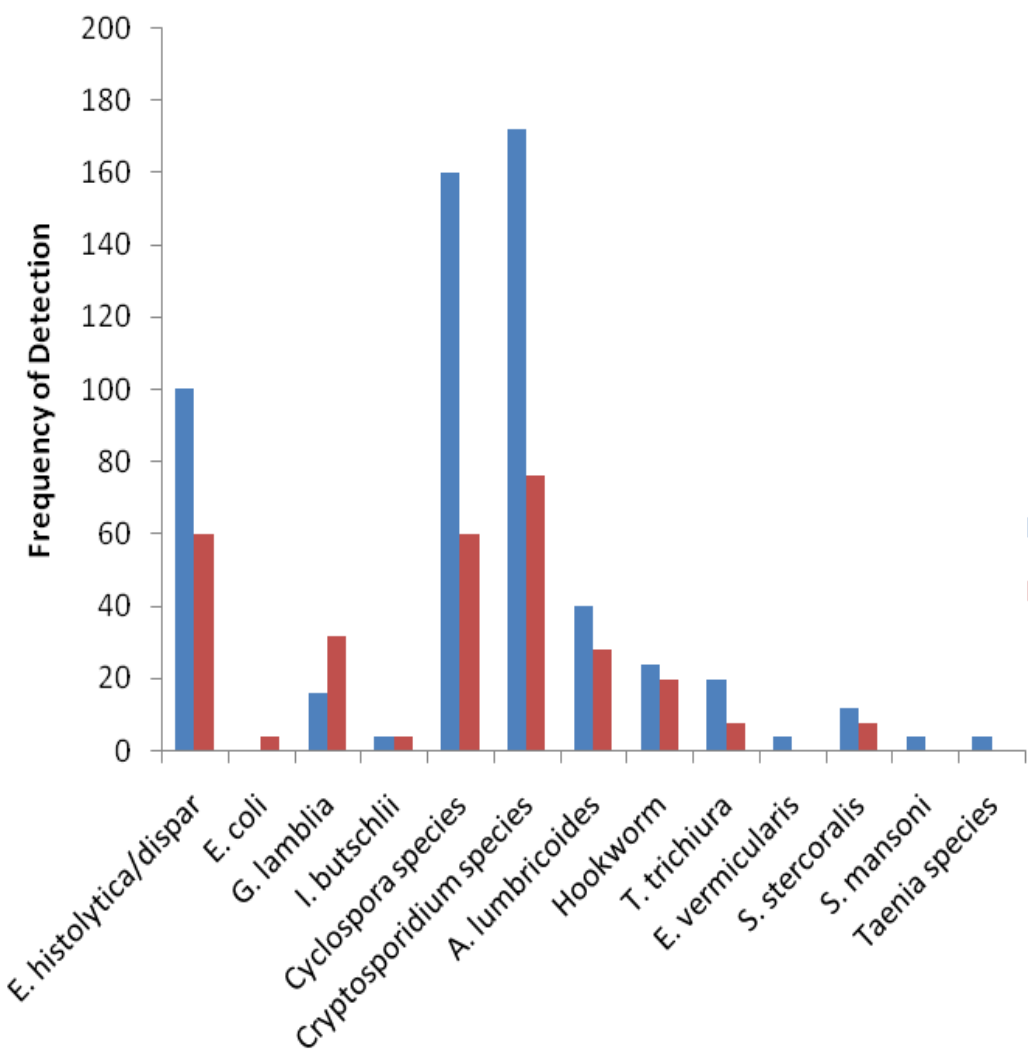

Parasites

Figure 1. Parasites Distribution among all Patients and Patients with and without diarrhoea, November, 2011-October, 2012.

patients without diarrhoea $(7.7 \%)$, this difference was significantly higher at $\mathrm{P}<0.05$.

\section{DISCUSSION}

To date few enteroparasitologic studies that included intestinal coccidian parasites have been carried out; most of the published studies have demonstrated the existence of the regular intestinal parasitoses parasites in this tropical region. Diarrhoea occurs worldwide and is responsible to $4 \%$ of all death and $5 \%$ of health loss disability (Nichols, 2000; WHO, 2000). For this reason the causes of infective diarrhoea illness should have to be properly investigated and established so that appropriate treatment may be instituted.

The importance of parasitic cause of diarrhoea such as 
Table 2. Coccidian parasites among all Patients and among patients with diarrhoea and non-diarrhoea November, 2011-October 2013.

\begin{tabular}{lcc}
\hline Parasite & Diarrhoea case $(\mathbf{n}=\mathbf{5 4 4})$ & Non-Diarrhoea case $(\mathbf{n}=\mathbf{4 9 6})$ \\
\hline Cryptosporidium & $150(27.6)$ & $47(9.5)$ \\
Cyclospora & $128(23.5)$ & $51(10.3)$ \\
Cryptosporidium/Cyclospora & $189(34.7)$ & $38(7.7)$ \\
\hline
\end{tabular}

E. histolytica/E. dispar, Trichuris trichiura and Giardia. lamblia has been well established (Roche and Benito, 1999; Oyerinde et al., 1989; Lopaz et al., 2003). There are variations in reports of prevalence of these parasites even within the same country. The prevalence found in the present study was lower compared to the findings of Alakpa and Fagbenro-Beyioku (2002) that reported a prevalence of 22, 19 and $9 \%$ in E. histolytica/dispar, $T$. Trichiura and G. lamblia respectively, which was higher than 4.5, 5.0 and $8.6 \%$ reported by Nwabuisi (2001) in Ilorin and also differ from our present study of prevalence of $12.7,3.6$ and $1.9 \%$ respectively.

Average prevalence of intestinal parasites in Africa countries was between 5 to $60 \%$ (Stephenson et al., 1989; Agi, 1995; Utzinger et al., 1999), which are in consonant with the results of this study. Eggs/larvae of helminth such as hookworm (Ancylostoma duodenale/Nectar americanus) as well as Ascaris lumbricoides, Trichuris trichiura, Enterobus vermicularis and Strongyloides stercoralis were detected in faeces, with prevalence of $4.2,6.5,2.7,0.4$ and $1.9 \%$, respectively. Despite the low prevalence of these worms found in the present study, the public health concern, especially for children, should be considered. These worms have been implicated in growth retardation of children in previous studies (Agi, 1995). Ascariasis causes vitamin A deficiency and possibly malnutrition as secondary effects; strongylodiasis has been implicated in competing for nutrients in the digestive tracts and enterobiasis cause intense irritation around the anus leading to loss of sleep (Utzinger et al., 1999). Other parasitic helminths found were Taenia species and Schistosoma mansoni were also reported by researchers in other tropical countries (Bathany et al., 2006).

Curiously, the prevalence of parasites was slightly higher in age group 41 to 50 years (27.3\%) and followed by age group 11 to 20 years (26.2\%) among patients with diarrhoea but not significant ( $p$ value 0.9 ). The reason for slight high prevalence among these age groups is not known, however, it may be attributed to poor personal hygiene, poor sanitary conditions and contaminated food or water among others.

The result from this study has shown that Cryptosporidium species is the most frequent intestinal parasite in llorin (23.8\%). A seroprevalence of above $32 \%$ of Cryptosporidium species has been reported for some West African countries (Nwabuisi, 1998) and a prevalence of $29 \%$ was reported in Lagos, Nigeria (Alakpa and Fagbenro-Beyioku, 2002). Another study carried out in llorin reported a prevalence of $15.1 \%$ among diarrhoeic patients (Nwabuisi, 2001).

Cyclospora cayetanensis has been reported in tropical countries including Nigeria (Alakpa and FagbenroBeyioku, 2002; Karanja et al., 2007). In this study, a prevalence of $21.1 \%$ was obtained in all the patients studied and a prevalence of $29.4 \%$ among patients with gastrointestinal illness. Cyclospora cayetanensis has been known to be responsible for outbreak of diarrhoea illness in United State and Canada (CDC, 2008; Cann, 2000). It has been reported as agent of travellers' diarrhoea in European countries (Cann et al., 2000; Doller et al., 2002). In some tropical countries where the parasite is known to be endemic, it has been reported to cause short-lived and self limiting diarrhoea among the immunocompetent individuals (Nassaf et al., 1998; Mansfield and Gajadhar, 2004). In Turkey where 130 stools of immunocompetent patients with diarrhoea were examined for Cyclospora cayetanensis a prevalence of $9.2 \%$ was reported (Meral et al., 2004; Meral, 2004). The detection of oocysts of this agent in stool samples of immunocompetent individual without diarrhoea provided much needed information on epidemiology and endemicity of this organism in llorin, Nigeria. Although we are of the opinion that further studies is needed to establish the effect of asymptomatic carriage of this coccidian parasite at other centres.

\section{Conclusion}

In conclusion, the findings in this study have shown that Cyclospora cayetanensis and Cryptosporidium are endemic and most prevalent in llorin. Since the prevalence of these parasites is higher than those regular intestinal parasites, the hospital laboratories should include the search for these coccidian parasites in routine procedure in the diagnosis of unexplained diarrhoea illness. However, short term measures can play an effective role in reducing the transmission of infectious diarrhoea disease through health education at all levels of health care delivery, simple and consistent hand washing, improved personal hygiene, treatment of public water supply, and control of domestic animals that may serve as reservoirs (Helmay, 2010). 


\section{REFERENCES}

Agi PI (1995). Pattern of Infection of Intestinal Parasites in Saybama Community of Niger Delta, Nigeria. West African J. Med. 14:39-42

Alakpa GE, Fagbenro-Beyioku AF (2002). Cyclospora cayetanensis and intestinal Parasitic Profile in Stool Samples in Lagos, Nigeria; Acta Protozoologic. 41:221-229

Bethany J, Simon B, Marco A, Stefan GM, Loukas A, Diemert D, Hotez PJ (2006). Soil-transmitted helminth infections: ascariasis, trichuriasis, and hookworm. The Lancet. 367:1521-1532

Cann KJ, Chalmers RM, Nichola G, O'Brien SJ (2000). Cyclospora Infection in England and Wales, 1993 to 1998. Communicable Disease and Public Health. 3:46-49

Centers for Disease Control and Prevention (2008). Surveillance of laboratory-confirmed sporadic cases of cyclosporiasis-United States. 1997-2008, MMWR Surveil. Summ. 60(2):1-11

Centre for Disease Control and Prevention (2004). Outbreak of cyclosporiasis associated with snow peas-Pennsylvania. MMWR. 53:876-878.

Cheesbrough M (2005). District Laboratory Practice in Tropical Countries. Part 1. Cambridge University Press. pp. 86-100.

Connor B, Johnson E, Soare R, (2001). Reita Syndrome following protected synptoms of Cyclospora infection. Emerging Infectious Dis. $7(2): 453-454$

Doller PC, Dietrich K, Filipp N (2002). Cyclosporasis Outbreak in Germany Associates with Comsumption of Salad. Emerging Infectious Diseases. 8:992-994

Ellicott EJ (2007). Acute Gastroenteritis in children. BMJ 304:35-40

Farting MJ, (2000). Clinical aspects of human cryptosporidiosis. Conrib. Microbiol. 6:50-74

Helmay MM, (2010). Cyclospora cayetanensis: a review, focusing on some of the remaining questions about cyclosporiasis.

Karannja RM, Gatel W, Wamae N (2007). Cyclosporiasis: an emerging public health concern around the world and in Africa. Afr. Health Sci. 7(2):62-67.

LOpez AS, Bendik JM, Alliance TY, Roberts HM, da Silva AJ, Moura IN, Arrowood MJ, Eberhard ML, Herwardt BL (2003). Epidemiology of Cyclospora cayetanensis and other Intestinal Parasites in a Coummunity of Haiti. J. Clin. Microbiol. 41(5):2047-2054.

Logar J, Polzsek-prijatelj M, Andlorie A (1997). Cyclospora cayetanensis Potential Cause of Diarrhoea (Letter). J. Infection. 24:248-285.

Meral T, Metin T, Mucide AK, Berrin K, Turan K (2004). Cyclosporasis Associated with Diarrhoea in an Immunocompetent Patient in Turkey. J. Med. Microbiol. 53:255-257.

Nassaf ME, el-Ahl SA, el-Shafee OK, Nawar M (1998). Cyclospora in Egypt. J. Eqypt Soc. Parasitol. 28:213-219.
National Population Commission (NPC) (2006)

Nichols GL (2000). Food borne protozoa. Br. Med. Bull. 56(1):2029 2035.

Nwabuisi C (2001). Childhood cryptosporidiosis and intestinal parasitosis in association with diarrhoea in Kwara State, Nigeria. West Afr J. Med. 20 (2):165-168.

Nwasbuisi C. (1998). Cryptosporidium among Diarrhoea patients in Ilorin, Nigeria. Nig. Med. Pract. 35 (3,4):39-41.

Ortega YR, Gilman RH, Sterling CR (1994). A new coccidian parasite (Apicomplexia, Eimeriidae) from humans. J. Parasitol. 80:625-629

Ortega YR, Sterling CR, Gilman RH, Cama VA, Diaz F (1998). Cyclospora species, new protozoan pathogen of humans. New England J. Med. 328:1308-1312.

Oyerinde JPO, Odugbemi T, Benson RI, Alonge, AA, Roberts JIK (1989). Investigation of Cryptopsoridium in relation to other intestinal parasites at the Lagos University Teaching Hospital, Lagos. West African J. Med. 8:264-269.

Popovici I, Dahorea C, Rugina, A, Coman G (2003). Acute diarrhoea with Cyclospora cayetanensis. Rev. Med. Chir. Soc. Med. Nat. Lasi. 107(4):877-880

Quivoz ES, Bern C, MacArthur JR, Xiao L, Fletcher M, Arrowwood MJ, Levy ME, Glass RI, Lal A (2000). An outbreak of cryptosporidiosis linked to a foodhamdler. J. Infect. Dis. 181:695-700.

Ramirez NE, Ward LA, Sreevatsan S (2004), A Review of Biology and Epidemiology of cryptosporidiosis in human and animals. Microbes and Infection. 6:773-785.

Ridley DS, Hawgood BC (1965). The value of formol-ether Concentration in faecal cysts and ova. J. Clin Pathol. 9:74-76.

Roche J, Benito A (1999). Prevalence of Intestinal Parasitic Infections with Special Reference to Entamoeba histolytica on the Island of Bioko (Equatorial Guinea). Am J Trop Med Hygiene. 60(2):259-262

Shields JM, Olson BH, (2001). Cyclospora cayetanensis: a review of an emerging parasitic coccidian. Int. J. Parasit. 33(4):371-391.

Stephenson LS, Lathan MC, Kurtz KM, Kinoti SN, Brigham H (1989). Treatment with a Single Dose of Albendzole Improves Growth of Kenyan School Children with Hookworm, Trichuris trichiura, and Ascaris lumbricoides. Am. J. Trop. Med. Hyg. 41:78-87.

Utzinger J, N'Goran EK, Marti HP, Tanner M, Lengeler J (1999). Intestinal Amoebiasis, Giardiasis and Geohelminthiasis: Their Association with other Intestinal Parasites and Reported Intestinal Symptom. Trans. R. Soc. Trop. Med. Hyg. 93:137-141.

WHO (2000) Global Water Supply and sanitation assessment, WHO, Geneva. 